\title{
Mechanical and Morphological Properties of Polypropylene/Polyoxymethylene Blends
}

\author{
Sirirat Wacharawichanant, Tanakorn Siripattanasak \\ Department of Chemical Engineering, Faculty of Engineering and Industrial Technology, Silpakorn University, \\ Bangkok, Thailand \\ Email: wsirirat@su.ac.th,guitar_soda@hotmail.com
}

Received March 15, 2013; revised April 16, 2013; accepted May 8, 2013

Copyright (c) 2013 Sirirat Wacharawichanant, Tanakorn Siripattanasak. This is an open access article distributed under the Creative Commons Attribution License, which permits unrestricted use, distribution, and reproduction in any medium, provided the original work is properly cited.

\begin{abstract}
This work studies the mechanical and morphological properties of polypropylene (PP)/polyoxymethylene (POM) blends. The PP/POM blends were prepared by melting-blend with an internal mixer. The contents of PP were used at $10 \%$, $20 \%$, $30 \%, 70 \%, 80 \%$ and $90 \%$ by weight. The phase morphology of the blends was observed by scanning electron microscope (SEM) due to the mechanical properties depended on the phase morphology. The results show the decrease of the impact strength, Young's modulus and tensile strength of POM/PP blends with increasing of PP content up to 30 wt\% and then increase again with a high PP content. The percent strain at break of the blends increases after adding PP in a range of 70 - $90 \mathrm{wt} \%$. SEM study reveals that the POM/PP blends clearly demonstrate a two-phase matrix-particle microstructure. The results also show that the domain size of dispersed PP or POM phase increases with increasing PP or POM content. The POM domain size is smaller than the PP domain size which leads to a little change of mechanical results of PP.
\end{abstract}

Keywords: Polypropylene; Polyoxymethylene; Morphology; Mechanical Properties

\section{Introduction}

Blending two polymers to produce new and high-performance polymeric materials with targeted properties is a popular and attractive topic. The final aim is to promote synergism among the immiscible polymer pairs in order to form blends with enhanced or even new tailored properties with respect to those of the different polymers [1-4].

Polyoxymethylene (POM) is an excellent engineering thermoplastic, which is considered as an alternative for metals in many applications because of its remarkable mechanical and self-lubricating characteristics [5]. It is a lightweight, low-friction, and wear-resistant thermoplastic with good physical and processing properties and capable of operating at temperatures in excess of $90^{\circ} \mathrm{C}$ [6]. The POM blends have been less studied, for example, Wang [7] studied the thermal stability of POM and Its blends with poly(ethylene-methylacrylate) (EMA) or poly (styrene-butadiene-styrene) (SBS). The results were reported that POM blends with SBS or EMA had similar degradation behavior as POM, but addition of SBS accelerated the POM degradation significantly. Degra- dation in POM and SBS/POM occurred in amorphous phase while EMA/POM degraded in both amorphous and crystal phase.

Polypropylene (PP) is one of the most widely used commodity polymers with the high heat distortion temperature and economic merits. However, the use of the $\mathrm{PP}$ is restricted by the low impact strength at the subambient temperature [8]. A blend of POM/PP is significant interesting, thus this work studies the mechanical and morphological properties of PP/POM blends. The phase morphology of one polymer and the blends was observed by scanning electron microscope (SEM).

\section{Experimental}

\subsection{Materials}

POM (DURACON M90-44) with the melt flow rate of $8.9 \mathrm{~g} / 10 \mathrm{~min}$ and specific gravity of 1.41 was produced by Polyplastics Company. PP (Mophen HP400K) was produced by HMC Polymer Company with the melt flow rate of $4 \mathrm{dg} / \mathrm{min}$. 


\subsection{Sample Preparation}

All types of polymers were dried before blending, POM and $\mathrm{PP}$ was dried in an oven at $110^{\circ} \mathrm{C}$ for $4 \mathrm{~h}$. PP/POM blends were prepared by melt blending in an internal mixer at $200^{\circ} \mathrm{C}$ and a rotor speed of $50 \mathrm{rpm}$ for $10 \mathrm{~min}$. The copolymer contents were 10, 20, 30, 70, 80 and 90 wt\% POM content. The samples for tensile and Izod impact tests were prepared by a compression molding at $200^{\circ} \mathrm{C}$ for $20 \mathrm{~min}$. Dumbbell samples for tensile test and rectangular samples for Izod impact test.

\subsection{Sample Characterization}

The impact test was performed with a Zwick/material testing August-Nagelstr.11.D-89079 Ulm at room temperature. Tensile tests were conducted according to ASTM D 638 with a universal tensile testing machine (LR $50 \mathrm{k}$ from Lloyd instruments) at a crosshead speed of $50 \mathrm{~mm} / \mathrm{min}$. Each value obtained represented the average of five samples.

The thermal stability and decomposition temperature of polymer blends were measured by thermogravimetric analysis (TGA) (Model SDT Q600, TA Instruments, England). The temperature was in the range of $30^{\circ} \mathrm{C}$ $600^{\circ} \mathrm{C}$ at a heating rate of $10{ }^{\circ} \mathrm{C} / \mathrm{min}$ under nitrogen atmosphere.

SEM (Model Maxim 2000S, CamScan Analytical, England) was taken to study the morphology of the $\mathrm{POM} / \mathrm{PP}$ blends. The accelerating voltage of SEM observation is $15 \mathrm{kV}$. The impact-fractured surfaces of the $\mathrm{POM} / \mathrm{PP}$ blends obtained from impact test were examned. All specimens were coated with gold before SEM observations.

\section{Results and Discussion}

The notched Izod impact strength of POM/PP blends is presented in Figure 1. It can be seen that the impact strength of POM/PP blends decreases with increasing PP contents until $30 \mathrm{wt} \%$ and then slightly increases but the impact strength is still lower than neat POM. Moreover, the result shows that the neat POM is higher impact strength than the neat PP so the addition of PP may affect the decrease of impact strength of the blends.

Figure 2 illustrates the trend of the tensile strength of POM/PP blends. The tensile strength of the blends decreases continuously with increasing PP content and small changes in a range of $70-100 \mathrm{wt} \% \mathrm{PP}$. The neat $\mathrm{POM}$ is higher tensile strength than the neat PP so the addition of PP may affect the decrease of tensile strength of the blends same as the impact strength. Figure 3 presents Young's modulus of POM/PP blends, it can be seen that Young's modulus decreases continuously with increasing PP content up to $30 \mathrm{wt} \%$ and then slightly in-

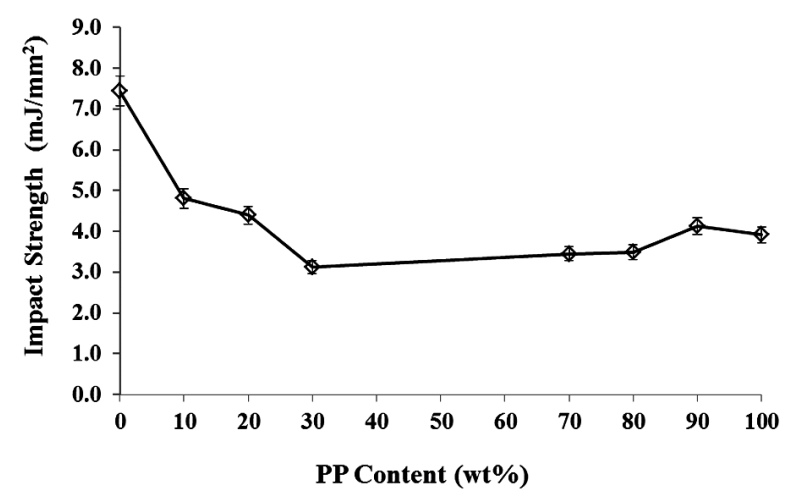

Figure 1. Impact strength of POM/PP blends.

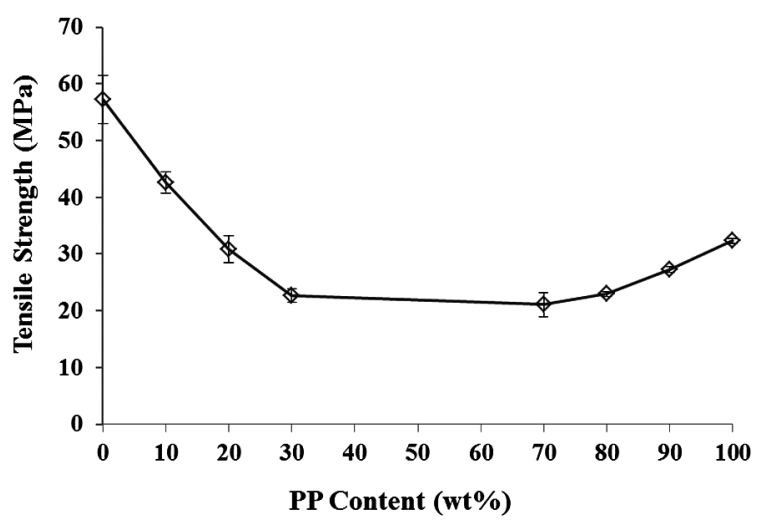

Figure 2. Tensile strength of POM/PP blends.

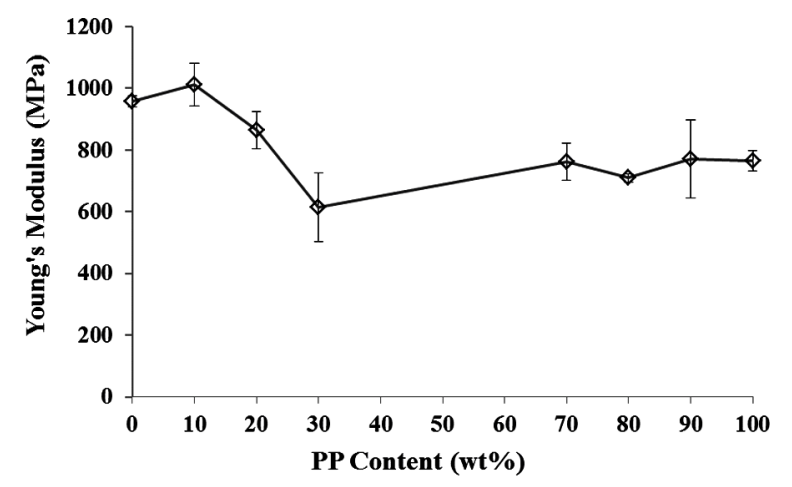

Figure 3. Young's modulus of POM/PP blends.

creases and maintains after adding PP 70 - 90 wt\%. Figure 4 presents the percent strain at break of POM/PP blends. The result shows the decrease of the percent strain at break of the blends in the low PP content and the improvement of the percent strain at break of the blends after adding PP 70 - $90 \mathrm{wt} \%$.

The thermal stability of the POM/PP blends with different amounts of PP was investigated by TGA. The degradation temperatures corresponding to the $5 \%$ weight loss (Td5) and 50\% weight loss (Td50) were calculated and are shown in Figure 5. The result shows the incurporation of PP improves the degradation temperature of 


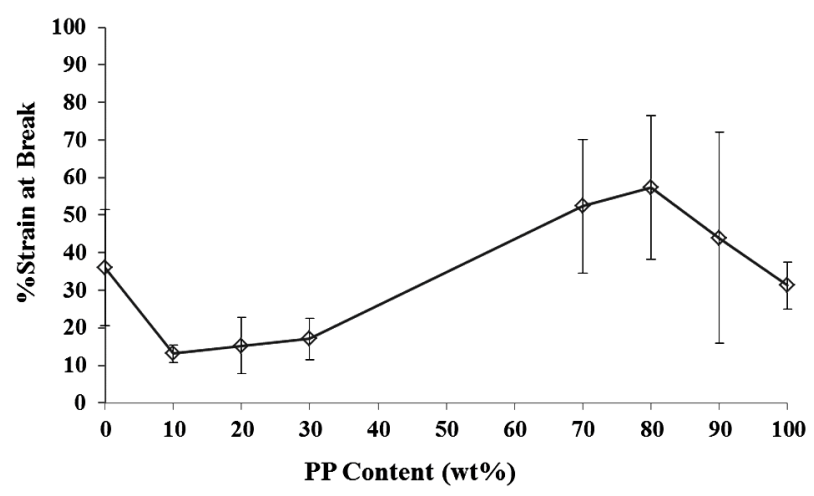

Figure 4. The percent stain at break of POM/PP blends.

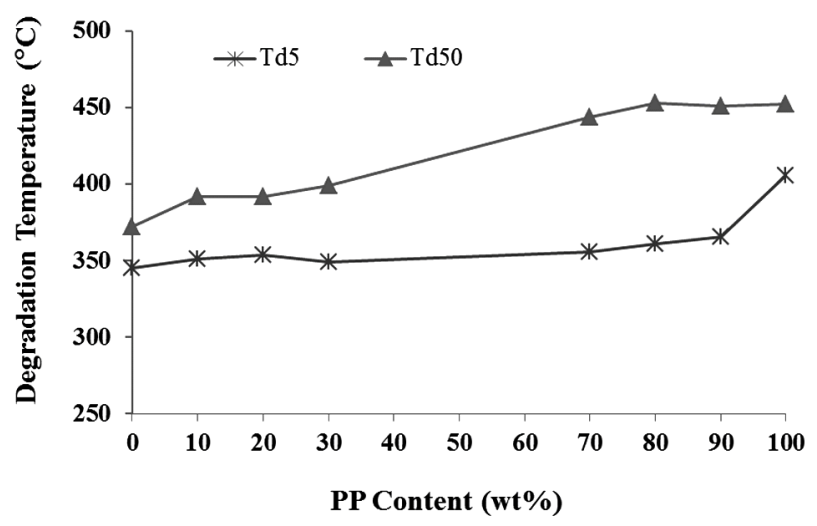

Figure 5. The degradation temperature of POM/PP blends.

POM. The degradation temperature of POM/PP blends increases with increasing PP content. This indicates that an improvement in the thermal stability in the POM/PP blends that depends on PP content due to PP has the high degradation temperature.

The SEM micrographs of pure POM and pure PP are presented in Figure 6. The fractured surface of pure POM and pure PP is a roughness, which referred to the typical characteristic of ductile fracture behavior. The SEM micrographs of POM/PP blends with different PP content are displayed in Figure 7. Figures 7(a)-(f) show SEM images of POM/PP blends with PP content of 10 , 20, 30, 70, 80 and $90 \mathrm{wt} \%$, respectively. The POM/PP blends clearly demonstrate a two-phase matrix-particle microstructure and blending POM with PP leads to a thermodynamically immiscible two-phase system. For 10 30 wt\% of PP (Figures 7(a)-(c)), the images observe that the minor phase of PP disperses as spherical domains in POM matrix and the domain size of dispersed PP phase increases with increasing PP content. In a case of 70 - 90 wt\% of PP (Figures 7(d)-(f)), the images display the minor phase of POM disperses as spherical domains in PP matrix and the domain size of dispersed POM phase increases with increasing POM content.

The dispersed phase form in spherical domains because a spherical particle has the minimal surface area,

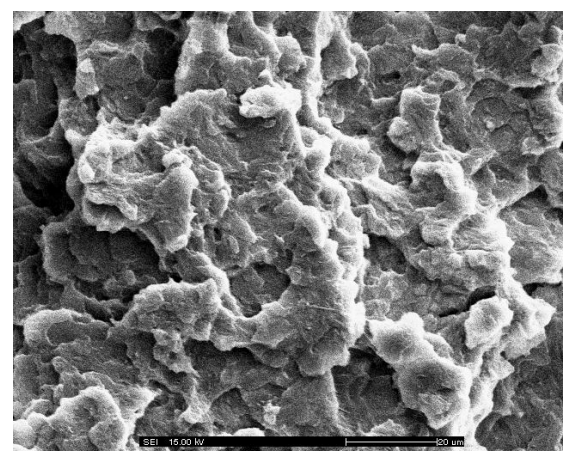

(a)

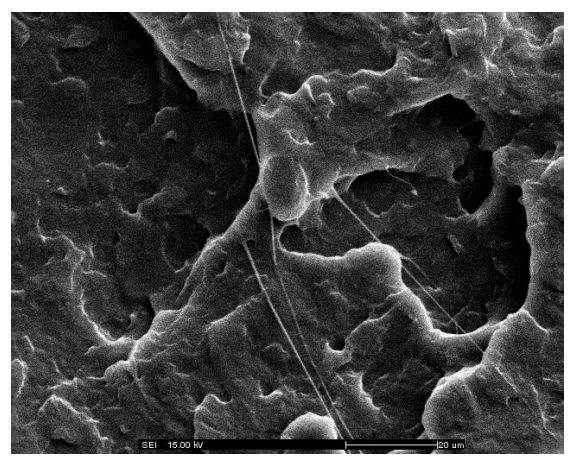

(b)

Figure 6. SEM micrographs of (a) pure POM and (b) pure PP.

thus minimize their surface area to volume ratio and hence limit the free energy of the blend by minimizing the surface energy at the continuous matrix/dispersed droplet interface [9]. In addition, the dispersed phase as larger spherical domains in matrix phase and the microvoids surrounding the PP or POM droplets indicate weak interfacial adhesion in the blends due to the immiscible nature of the polymers $[4,9,10]$. However, the domain size of dispersed POM phase is smaller than that of dispersed PP phase in the same content of PP or POM. This observation support the results of mechanical properties which indicates that the addition of POM in a range of 10 $30 \mathrm{wt} \%$ has less effect on the tensile and impact properties of neat PP.

\section{Conclusion}

The mechanical and morphological properties of PP/ POM blends are studied in this work. The results show the decrease of the impact strength, tensile strength and Young's modulus with increasing of PP content until 30 $\mathrm{wt} \%$ and then increase in a range of $70-90 \mathrm{wt} \%$ of PP. The percent strain at break of the blends decreases after adding low PP content and increases after adding high PP content. SEM study reveals that PP phase disperses in POM matrix in a range of $10-30 \mathrm{wt} \%$ of PP, but POM phase disperses in PP matrix in a range of $10-30 \mathrm{wt} \%$ of POM. The morphology reveals the microvoids surround- 


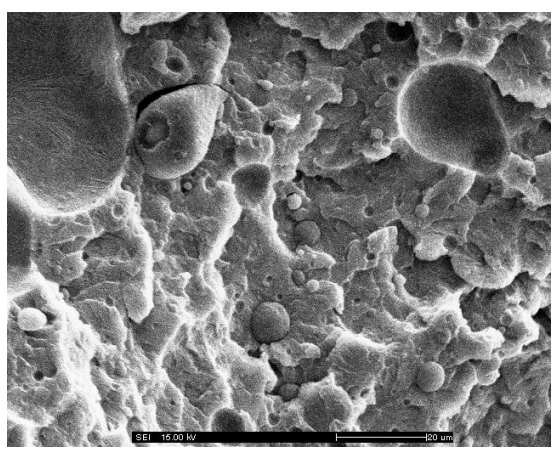

(a)

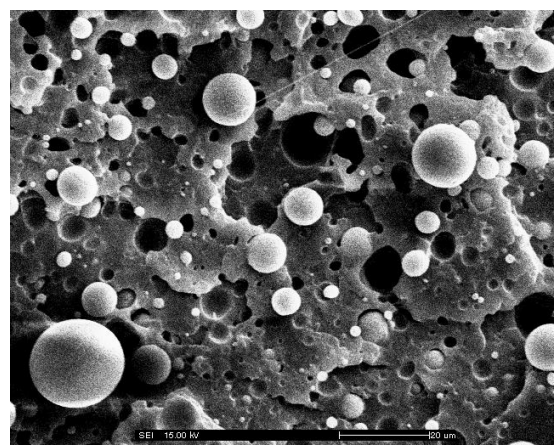

(d)

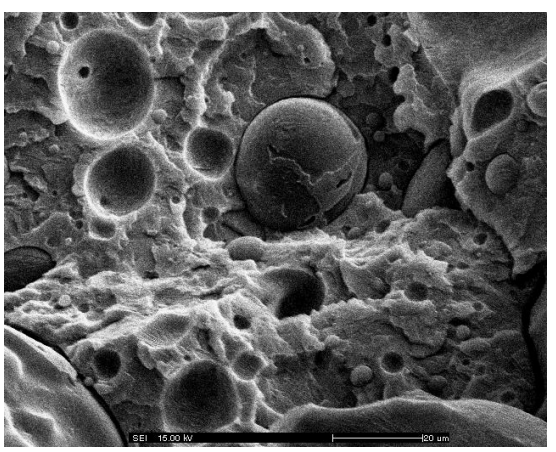

(b)

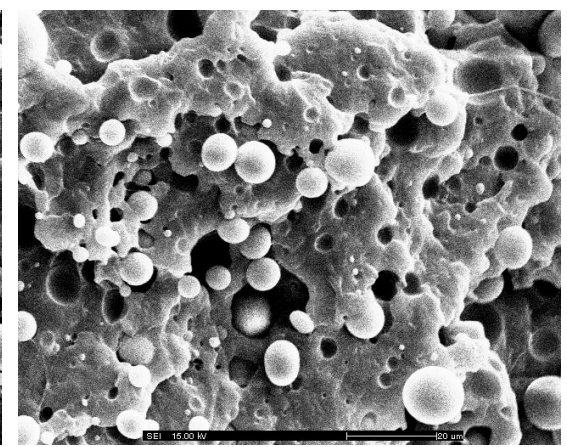

(e)

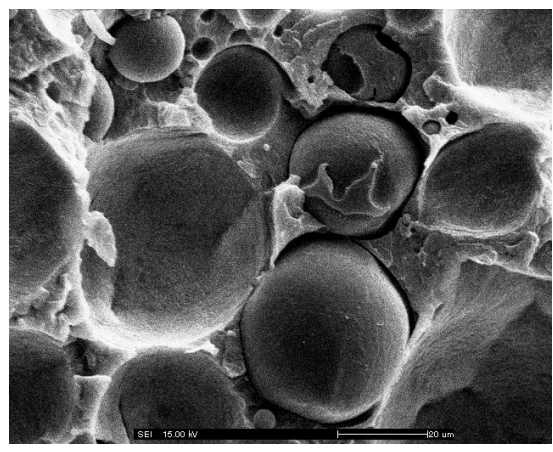

(c)

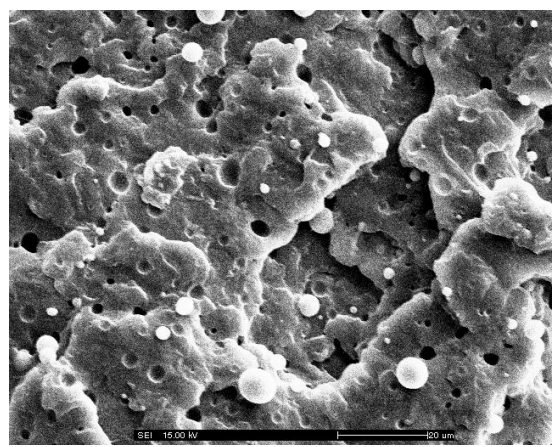

(f)

Figure 7. SEM micrographs of POM/PP (a) 90/10, (b) 80/20, (c) 70/30, (d) 30/70, (e) 20/80 and (f) 10/90.

ing the PP or POM droplets indicate weak interfacial adhesion in the blends due to the immiscible nature of the polymers. The results also show that the domain size of dispersed PP or POM phase increases with increasing PP or POM content. The POM domain size is smaller than the PP domain size which leads to a little change of mechanical results of PP.

\section{Acknowledgements}

The authors would like to thank Silpakorn University Research and Development Institute (SURDI) for the financial support of this project.

\section{REFERENCES}

[1] R. Scaffaro, M. C. Mistretta and F. P. La Mantia, "Compatibilized Polyamide 6/Polyethylene Blend-Clay Nanocomposites: Effect of the Degradation and Stabilization of the Clay Modifier," Polymer Degradation and Stability, Vol. 93, 2008, pp. 1267-1274.

[2] S. Mallick, A. K. Dhibar and B. B. Khatua, "Effect of Nanoclay on the Morphology and Properties of Poly(methyl methacrylate)/High-Density Polyethylene Blends,” Journal of Applied Polymer Science, Vol. 116, 2010, pp. 1010-1020.

[3] L. Wang, Z.-X. Guo and J. Yu, "Effect of Compounding Sequence on the Morphology of Organoclay-Filled PA6/ PP/MAPP Blends," Journal of Applied Polymer Science, Vol. 120, 2011, pp. 2261-2270.
[4] S. Mallick and B. B. Khatua, "Morphology and Properties of Nylon6 and High Density Polyethylene Blends in Absence and Presence of Nanoclay," Journal of Applied Polymer Science, Vol. 121, 2011, pp. 359-368.

[5] A. J. Jose and M. Alagar, "Development and Characterization of Organoclay-Filled Polyoxymethylene Nanocomposites for High Performance Applications,” Polymer Composites, Vol. 32, 2011, pp. 1315-1324.

[6] S. Srivastava, S. J. La’Verne, I. A. Khan, P. Ali and V. D. Gupta, "Phonons and Heat Capacity of Polyoxymethylene,” Journal of Applied Polymer Science, Vol. 122, 2011, pp. 1376-1381.

[7] Q. Wang, "Thermal Stability of Polyoxymethylene and Its Blends with Poly(ethylene-methylacrylate) or Poly(styrene-butadiene-styrene)," Journal of Applied Polymer Science, Vol. 121, 2011, pp. 376-388.

[8] C. K. Kum, Y.-T. Sung, Y. S. Kim, H. G. Lee and W. N. Kim, "Effects of Compatibilizer on Mechanical, Morphological, and Rheological Properties of Polypropy-lene/poly(acrylonitrile-butadiene-styrene) Blends,” Macromolecular Research, Vol. 15, 2007, pp. 308-314.

[9] S. Mallick, P. Kar and B. B. Khatua, "Morphology and Properties of Nylon 6 and High Density Polyethylene Blends in Presence of Nanoclay and PE-g-MA,” Journal of Applied Polymer Science, Vol. 123, 2012, pp. 18011811.

[10] A. K. Dhibar, J. K. Kim and B. B. Khatua, "Cocontinuous Phase Morphology of Asymmetric Compositions of Poly-propylene/High-Density Polyethylene Blend by the Addition of Clay," Journal of Applied Polymer Science, Vol. 119, 2011, pp. 3080-3092. 